\title{
SPLIT SECOND ANALYSIS COVERING HIGH PRESSURE GAS FLOW DYNAMICS AT PIPE OUTLET - MATHEMATICAL / CFD INVESTIGATION.
}

\author{
Ali Hasan \\ KEO International Consulting Engineers POB 18108
}

\begin{abstract}
A detailed investigation covering piped gas flow characteristics in high pressure flow conditions. Such flow analysis can be resolved using established mathematical equations known as the Fanno condition, which usually cover steady state, or final flow conditions. However, in real life, such flow conditions are transient, varying with time. This paper uses CFD analysis providing a split second "snapshot" at what happens at the pipe outlet, and therefore, a closer understanding at what happens at the pipe's outlet in high pressure gas flow condition.
\end{abstract}

In this example air was selected for simulation purposes. In HVAC applications, such gas flow conditions can occur in typical applications such as; air compressors releasing high pressure air through a pipe, or compressor over pressure refrigerant gas being released into the atmosphere via a discharge pipe.

Investigation has shown that rather than a steady mass flow rate condition occurring at the pipe outlet, calculated by the Fanno flow condition, a spiked increase in flow rate occurs at the beginning,and then stabilizing after a few seconds, with relatively minor ripples in flow rate. Other observations were also made and commented.

CFD results in mass flow rate were compared with the mathematically derived results, differences were recorded. The CFD analysis showed how the k-omega turbulence model performed well, with the processor stabilizing at an early stage.

\section{INTRODUCTION}

Whether it's an engine exhaust pipe or a compressed pressure vessel discharging through a pipe into the atmosphere, Fanno equations are important. Fanno flow refers to adiabatic flow in a pipe or duct where wall friction effects are considered. According to Equations EthirajanRathakrishnan 2008 [1], friction has the net effect of accelerating a subsonic stream, and causes a rise in static pressure at supersonic speeds

Published mathematical equations associated with high pressure flow taking into account fluid and thermodynamic effects can be used to resolve high pressure gas flow characteristics in pipes. EthirajanRathakrishnan 2008 [1] explains how viscous effects (friction) may have decisive effects on the resultant flow where high speed flow travelling through passages of sufficient length,

DOI : $10.5121 / \mathrm{aeij} .2015 .2401$ 
using mathematical equations to demonstrate such effects. Such equations are relatively easy to use and provide final steady state results. That's where the advantages of CFD analysis surface, in that, a detailed "split second" investigation can be carried out and basically providing graphical images of what actually takes place over a period of time.

The investigation has shown that when transient analysis is run, a spiked change in mass flow rate occurs in the outlet, and then almost immediately stabilizing with minor repel effects occurring at the outlet.

Possible examples applications of such simulation in relation to the HVAC industry; over pressure refrigerant discharge (through a pipe) from a chiller, and any high pressure fluid gas flowing through a pipe and discharging into the atmosphere.

\section{High pressure flow in pipes - gas dynamics}

An example highlighting the importance of Fanno flow conditions is given in a paper by Marco Cioffi (2013) [2]; blow-off lines in axial gas turbines are analyzed by adopting an adiabatic quasione-dimensional model of the gas flow through a pipe with a constant cross-sectional area and involving geometrical singularities (Fanno flow). Blow-off lines are installed to avoid dangerous flow instabilities during start-up and shut-downs.

B. S. Massey 1983 [3] refers to work carried out by Gino GirolamoFanno an Italian mechanical engineer who developed the Fanno flow model. Fanno flow refers to adiabatic flow through a pipe/duct of constant cross sectional area. Flow is assumed to be steady and that no mass or external work is added. Friction and compressibility effects play a role in determining the end flow result.

In a sufficiently long pipe/duct with an upstream $M>1$, deceleration occurs and the flow can become choked. On the other hand, $\mathrm{M}<1$, acceleration occurs and the flow can become choked. B.S. Massey 1983 [3] also states that maximum entropy occurs at $M=1$.

Y. Nakayama 2000 [4] states, since an actual flow of compressible fluid in pipe lines and similar conduits is always affected by the friction between the fixed wall and the fluid, it can be adiabatic but not isentropic. Such an adiabatic but irreversible (i.e. non-isentropic) flow is called Fanno flow.

Victor 1 Streeter 1962 [6] describes how the equations of state can be developed, Entropy equation for adiabatic flow with no change in elevation;

$\mathrm{S}-\mathrm{d}_{1}=\mathrm{c}_{\mathrm{v}} \ln \left[\left(\mathrm{p} / \mathrm{p}_{1}\right)\left(\rho_{1} / \rho\right)^{\mathrm{k}}\right]$

(a)

The energy equation for adiabatic flow with no change in elevation;

$\mathrm{H} 0=\mathrm{h}+\mathrm{V}^{2} / 2$

Continuity equation for no change in area;

$\mathrm{G}=\rho \mathrm{V}$

Linking (a) and (b) to obtain equation of state, gives; 


$$
\mathrm{h}=\mathrm{c}_{\mathrm{p}} \mathrm{T}=\mathrm{c}_{\mathrm{p}} \mathrm{p} / \mathrm{R} \rho
$$

By eliminating $\mathrm{p}, \rho$, and $\mathrm{V}$ from equations (a) to (d), the following h-s equation can be produced:

$$
\mathrm{S}=\mathrm{s} 1+\mathrm{c}_{\mathrm{v}} \ln \left[\left(\rho_{1} / \mathrm{p}_{1}\right)\left(\mathrm{R} / \mathrm{c}_{\mathrm{p}}\right)(\sqrt{2} / G)^{\mathrm{k}-1}\right]+\mathrm{c}_{\mathrm{v}} \ln \left[\mathrm{h}(\mathrm{h} 0-\mathrm{h})^{(\mathrm{k}-1) / 2}\right]
$$

Assumptions made in developing equations (discussedabove); adiabatic but irreversible (i.e. nonisentropic).

The above equation was used to plot enthalpyagainstentropy or h-s diagram. The Fanno curve reaches a maximum entropy at $\mathrm{h}=0.833$ at which the flow is choked. Fanno curve shown in Appendix indicates states for a given Fanno flow condition. According to R.S. Brodkey1995 [7], each point on the Fanno curve represents a different momentum value, and that the change in momentum is attributed to the effects of friction.

A solved problem given by EthirajanRathakrishnan2008 [1]is shown in the following paragraph. The section CFD model, shows how such analysis can be performed using CFD, while the discussions sections explains what CFD can add to mathematically calculated results.

Consider the pipe dimensions given in Fig 1, with 13.8 bar pressure applied at the inlet, and discharging at the outlet at 0 gauge pressure. Inlet temperature $310 \mathrm{~K}$. Pipe wall friction 0.005 . The calculations will determine what pipe length will produce $2.25 \mathrm{~kg} / \mathrm{s}(4.95 \mathrm{lb} / \mathrm{s})$ mass flow rate at the outlet. Thus demonstrating through calculations how Fanno equations works, and then start CFD simulation for results comparison.

Let the subscripts $1 \& 2$ refer to conditions at entry and exit of the pipe, respectively.

$$
\begin{aligned}
& \dot{\mathrm{m}}=2.25 \mathrm{~kg} / \mathrm{s}(4.95 \mathrm{lb} / \mathrm{s}) \\
& \mathrm{G}=\frac{\dot{\mathrm{m}}}{\mathrm{A}}=\frac{2.25}{\left(\frac{\pi}{4}\right)(0.005)^{\wedge} 2}=0.1146 \mathrm{e} 4 \mathrm{~kg} / \mathrm{s}-\mathrm{m}^{2}\left(1.57 \mathrm{lb} / \mathrm{s}-\mathrm{in}^{2}\right) \\
& \mathrm{G}=\mathrm{p}_{1} \mathrm{M}_{1}\left(\frac{Y}{R T 1}\right)^{1 / 2}=\mathrm{p}_{2} \mathrm{M}_{2}\left(\frac{Y}{R T 2}\right)^{1 / 2}=\text { constant } \\
& \text { Now, } \mathrm{p}_{1} \mathrm{M}_{1}\left(\frac{Y}{R T 1}\right)^{1 / 2}=\mathrm{G} \\
& \text { Can be rewritten } \\
& \left(\mathrm{p}_{1} / \mathrm{p}_{0}\right)\left(\frac{\mathrm{T} 0}{\mathrm{~T} 1}\right)^{1 / 2} \mathrm{M}_{1}=\left(\frac{R}{V}\right)^{1 / 2} \mathrm{G}\left(\mathrm{T}_{0}^{1 / 2} / \mathrm{p}_{0}\right)=\left(\mathrm{RT}_{1}{ }^{\prime} Y\right)^{1 / 2} /{ }^{\prime} Y=\mathrm{G} / \mathrm{p}_{0} \\
& =\frac{352.9}{1.4} \times \frac{(\mathrm{i})}{1.1146 e 4} \\
& 0.209
\end{aligned}
$$

The LHS of equation (i) has three parameters and out of them the pressure ratio and temperature ratio are uniquely related to Mach number. By trials, we can solve this equation as follows: Let $\mathrm{M}_{1}=0.21$. Then;

$$
\begin{aligned}
& \text { LHS }=\frac{0.21 \times 0.9697}{\sqrt{0.9913}}=0.2045 \\
& \text { LHS }<\text { RHS } \\
& \text { Let } \mathrm{M}_{1}=0.22, \text { then; }
\end{aligned}
$$


LHS $=\frac{0.22 \times 0.9668}{\sqrt{0.9904}}=0.2137$

LHS > RHS

Hence, $M_{1}$ lies between 0.21 and 0.22 . For $M_{1}=0.213$, LHS is nearly equal to RHS. Therefore, $\mathrm{M}_{1}=0.213$ can be taken as the correct solution. For this value of $\mathrm{M}_{1}, \mathrm{p}_{1} / \mathrm{p}_{0}=0.969, \mathrm{p}_{1} / \mathrm{p}_{*}=5.12$

Thus, $\mathrm{p}_{1}=13.37 \mathrm{e} 5 \mathrm{~Pa}, \& \mathrm{P}_{*}=2.611 \mathrm{e} 5 \mathrm{~Pa}$

For $\mathrm{M}_{1}=0.213$, use the flow equation $4 \mathrm{f}\left(\mathrm{l}_{\max }\right) / \mathrm{D}=12.11$

$1_{\text {max }}=\frac{12.11 \times 0.05}{4 \times 0.005} \mathrm{~m}$

$1_{\max }=30.275 \mathrm{~m}(99.302 \mathrm{ft})$

Now we can start the CFD simulation in the following section.

\section{CFD model}

Model was prepared as shown in Fig 1. A CFD analysis was carried out using Fluent software with the following assumptions and settings;

(A) Pipe length and dimensions were assumed as shown in Fig 1. Rather than starting with figures on input pressure and required outlet flow, to calculate the pipe length. In this section "reverse calculations" were made, that is starting with the calculated pipe length of $30.275 \mathrm{~m}$ (99.302 ft), and input pressure of $13.8 \mathrm{bar}$, and obtain a CFD derived figure on pipe outlet flow rate. This will allow for a comparison between the CFD results and the worked out problem shown in the above section.

(B) Air as an ideal gaswas assumed.

(C) K-omega model was used, this model works well where adverse pressure gradients exist as expected in this simulation. Brian Spalding 2014 [5] describes the model as being suitable where adverse pressure gradients exist and numerically very stable, and that it tends to produce converged solutions more rapidly than the k-epsilon model.

(D.)Meshing use an Inflation mesh tool with default settings. This is important and contributes to stable numerical processing. See Fig 1 for details on inflated mesh layers along the pipe wall.

(E) Number of cells used 9,380,950. Mesh Metrics - Element Quality; Minimum element Jacobian 0.10, Maximum Element Jacobian1.00, Average Element Jacobian 0.53, Standard Deviation0.25. An Element Jacobian close to 1 indicates a good element quality, while an Element Jacobian close to 0 indicates a poor element quality.

(F) Settings not mentioned in this paper can be left at software default settings.

(G) Transient analysis was assumed with 70 time steps, each time step $0.05 \mathrm{~s}$.

(H) Pipe wall friction coefficient, 0.005 , similar to what is used in the worked out example shown in the above section.

(I) Adiabatic simulation considered. 


\section{RESULTS}

Graphical and numerical results were generated using the software post processor.Figures 2 to 4 show graphical results covering; mass flow rate, pressure, and TKE at outlet.

Comparing mass flow rate results obtained using the solved problem, and CFD has shown that a difference of $20.0 \%$ exists, calculated as follows: -

$$
\begin{aligned}
& \frac{\text { mass flow rate using } C F D-\text { mass flow rae using equations }}{\text { mass flow rate using equations }} \times 100 \\
& \frac{(2.7009-2.25)}{2.25} \times 100=20.0 \%
\end{aligned}
$$

The $2.25 \mathrm{~kg} / \mathrm{s}$ mass flow rate was calculated in the example calculation shown in the section on High pressure flow in pipes - gas dynamics. Therefore, the two methods can now be assessed for possible errors.

\section{DISCUSSIONS}

The following observationsare discussed in this section: -

Fanno curves and equations are connected with stable or final conditions. In real life this is not the case, transient flow occurs. Fluid gas flow characteristics and physical conditions are influenced, as it was observed in this CFD investigation. In this paper a transient flow simulation was considered over a period of 3.5 seconds. This has revealed the following observations made at the pipe outlet: -

Figure 2 shows the mass flow rate at the outlet beginning with a "spiked" flow. Relatively significant fluctuations exist up to time step 40 , and then relatively non-significant fluctuations observed at time step 40 and beyond.

Figure 3 shows that in the beginning of transient analysis the outlet pressure is high, and then begins to drop, and eventually stabilize after 70 time steps, that is $70 \times 0.05 \mathrm{~s}=3.5 \mathrm{~s}$. Type of curve can be described as an exponential decay. Where the pressure value gets smaller and smaller as the time step increases, with the curve never cuts through the $\mathrm{x}$-axis.

Figure 4 shows that TKE levels at the beginning are low, and then peak at 15 time steps, that is 15 $\times 0.05 \mathrm{~s}=2.5 \mathrm{~s}$. This plot indicates the mean kinetic energy per unit mass associated with eddies in turbulent flow which is known as the turbulence kinetic energy, at the outlet. According to Bengt Anderson 2012 [8], the intensities of velocity fluctuations in different directions can be measured in terms of the turbulent kinetic energy per unit mass, expressed as follows: -

$$
\mathrm{TKE}=\frac{1}{2}\left\{\left(\mathrm{u}_{1}^{2}\right)+\left(\mathrm{u}_{2}^{2}\right)+\left(\mathrm{u}_{3}^{2}\right)\right\}
$$

Simulation confirms what was stated by Brain Spalding 2014 [3] regarding the performance of the k-omega turbulence model and its suitability in handling adverse pressure conditions, as discussed in the CFD model section. 
Advanced Energy: An International Journal (AEIJ), Vol. 2, No. 4, October 2015

On the basis of referenced information and this analysis Fanno flow conditions must be considered for accurate gas dynamics calculations. CFD and theoretical methods are both important and knowing that possible differences can exist. The designer must therefore, carefully assess what methods to choose, whether it's a CFD or the theoretical equation. As mentioned in the example reference by Marco Cioffi (2013) [2], "Blow-off lines are installed to avoid dangerous flow instabilities during start-up and shut-downs." S.M. Yahya (2003) [9] notes that Fanno flow occurs in a number of practical situations, such as; flow process occurring in gas ducts of aircraft engines, air-conditioning systems. Steam pipe lines in power plants and other industrial applications where pipes are insulated to minimize heat loss and therefore (can be assumed adiabatic), Fanno flow conditions can be applied. Particularly in long ducts/pipes where wall frictions can significantly effect fluid parameters.

\section{CONCLUSION}

Investigations have shown how CFD can be used to predict Fanno flow conditions, rather than using the equations developed by Fanno. The CFD analysis has shown how a transient flow simulation can provide a wider understanding of what happens in such flow conditions. Careful considerations given to Fanno flow conditions can be important in avoiding dangerous flow instabilities depending on nature of application.

Steady state conditions can be calculated using the Fanno flow condition, however, in real life transient flow conditions occur, and therefore CFD is recommended.

CFD analysis showed that the flow pressure at the pipe outlet can be represented in the form of an exponential decay curve.

Turbulence Kinetic Energybegins at high levels coinciding with relatively spiked mass flow rates, and high pressure levels, and then reduced to lower levels as time moves on.

A difference of $20 \%$ occurred between the calculated mass flow rates figures, using CFD and the Fanno flow condition equation method.

CFD processor stabilized while processing at an early stage using the k-omega turbulence model. It is essential that an inflated mesh layer is established along the pipe wall.

\section{AKNOWLEDGEMENTS}

Thanks to;

- Prof EthirajanRathakrishnan 2008 [1] for providing information on the solved problem used in this paper.

- DrLikSim of Qatar University, Qatar. For software setting up and providing access.

\section{NOMENCLATURE}

$\mathrm{T}=$ Temperature, $\mathrm{To}=$ pipe inlet temperature, $\mathrm{T}_{1}-$ outlet temperature, $\mathrm{po}=$ pipe inlet pressure, $\mathrm{p}_{1}$ $=$ outlet temperature, $\mathrm{m}=$ meter, $\mathrm{ft}=$ feet, $\mathrm{mm}=$ millimeters, in $=$ inch, $\mathrm{M}=$ Mach number, $\mathrm{m} / \mathrm{s}=$ meters/second, $\mathrm{ft} / \mathrm{s}=$ feet per a second, $\mathrm{J} / \mathrm{kg}=$ Jeouls per a kilogram, Btu/lb $=$ British thermal units per a pound, ${ }^{\circ} \mathrm{C} /{ }^{\circ} \mathrm{K} /{ }^{\circ} \mathrm{F}=$ degrees Centigrade / degrees Kelvin / degrees Fahrenheit, $\Upsilon=$ 
ratio of specific heats of fluid, $\mathrm{R}=$ gas constant, $\mathrm{kg} / \mathrm{s}=\mathrm{kilograms} / \mathrm{second}, \mathrm{lb} / \mathrm{s}=$ pounds $/$ second, $\mathrm{CFD}=$ Computational Fluid Dynamics, TKE $=$ Turbulence Kinitec Energy, $c_{\mathrm{p}}$ and $\mathrm{c}_{\mathrm{v}}$ are specific heats at constant pressure and constatn volume respectively, $\mathrm{h}=$ enthalapy.

\section{REFERNCES}

[1] EthirajanRathakrishnan (2008). Gas Dynamics 2nd edition. Published by Prentice-Hall of India Ltd, India. P 272.

[2] Marco Cioffi, Enrico Puppo and Andrea Silingardi (2013). Fanno Design of Blow-off Lines Duty Gas Turbine. Published by ASME Turbo Expo 2013: Turbine Technical Conference and Expositio, Vol 4, Paper No. GT2013-95024.

[3] B. S. Massey (1983). Mechanics of Fluids 5th edition. Published by Van Nostrand Reinhold, UK. P 471.

[4] Y. Nakayama and R.F. Boucher (2000). Introduction to Fluid Mechanics (Butterworth-Heineman Edition) - 13.7 Fanno Flow and Rayleigh Flow. Published by Elsevier. P 235.

[5] Brian Spalding (2014). CHAM Ltd, Wimbledon, London, UK. The k-omega turbulence model.

[6] Victor L. Streeter (1962). Fluid Mechanics 3rd edition. Published by McGraw-Hill Book Company, Inc, USA. P 262.

[7] R.S. Brodkey (1995). The Phenomena of Fluid Motions. Published by R.S. Brodkey, USA. P 187.

[8] Bengt Anderson, Ronnie Anderson, and Love Hakansson (2012). Computational Fluid Dynamics for Engineers. Published by Cambridge University Press. P68.

[9] S.M. Yahya (2003). Fundamentals of compressible Flow. Published by New Age International (P) Ltd. New Delhi, India. P 265.

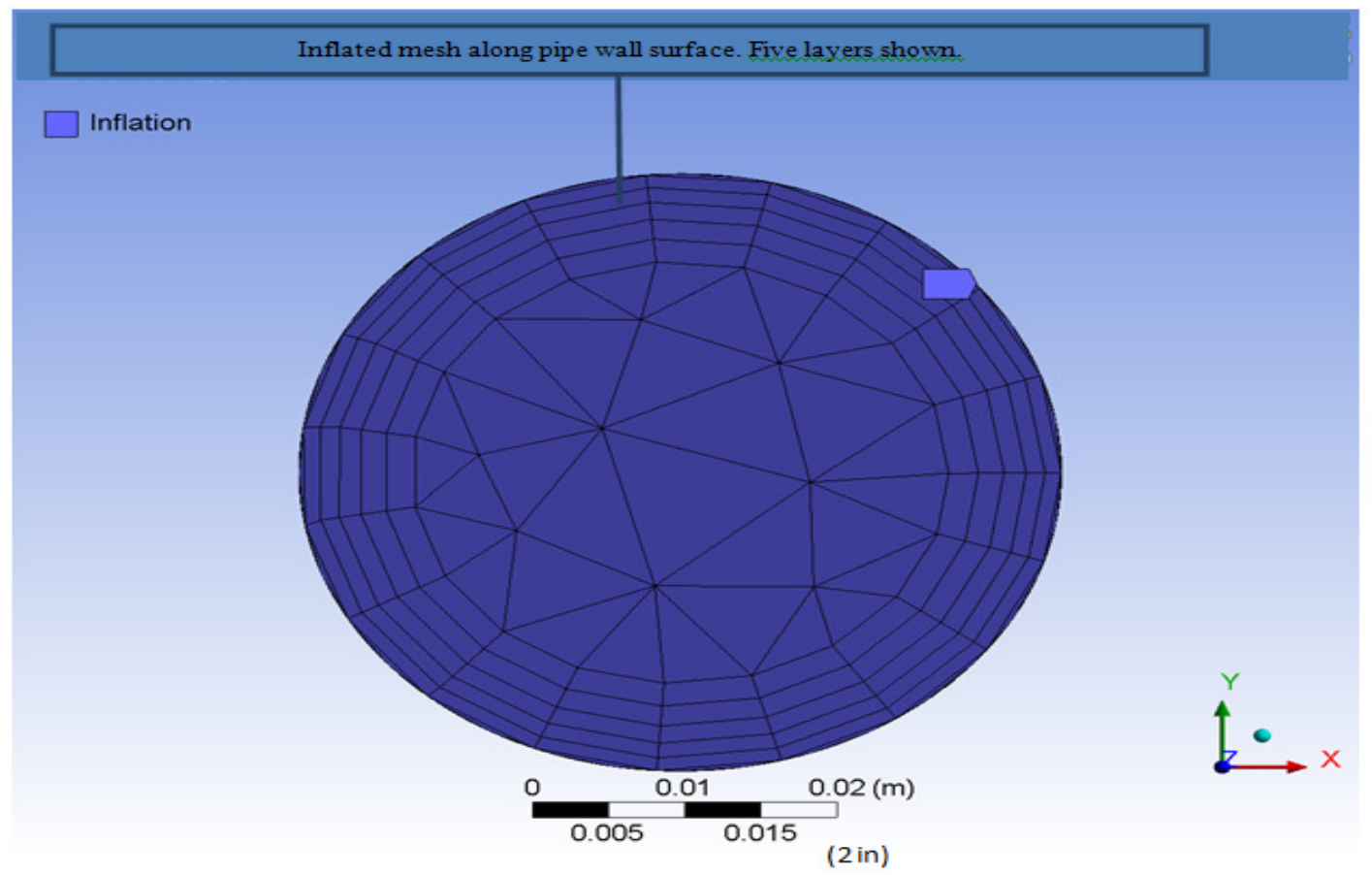

Figure 1. CFD model of pipe showing mesh with inflated mesh layers along pipe wall. Pipe diameter 0.05 m (2 in), length $30.275 \mathrm{~m}(99.302 \mathrm{ft})$, material Aluminum. 
Advanced Energy: An International Journal (AEIJ), Vol. 2, No. 4, October 2015

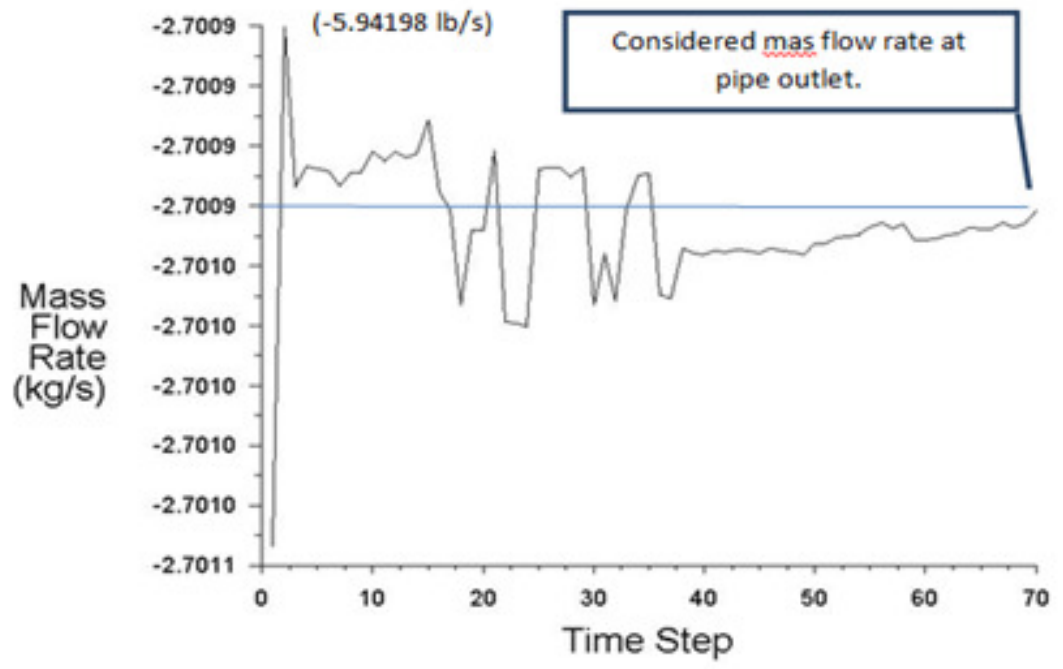

Convergence history of Mass Flow Rate

Figure 2.Monitoring mass flow rate at pipe outlet over a period of time.

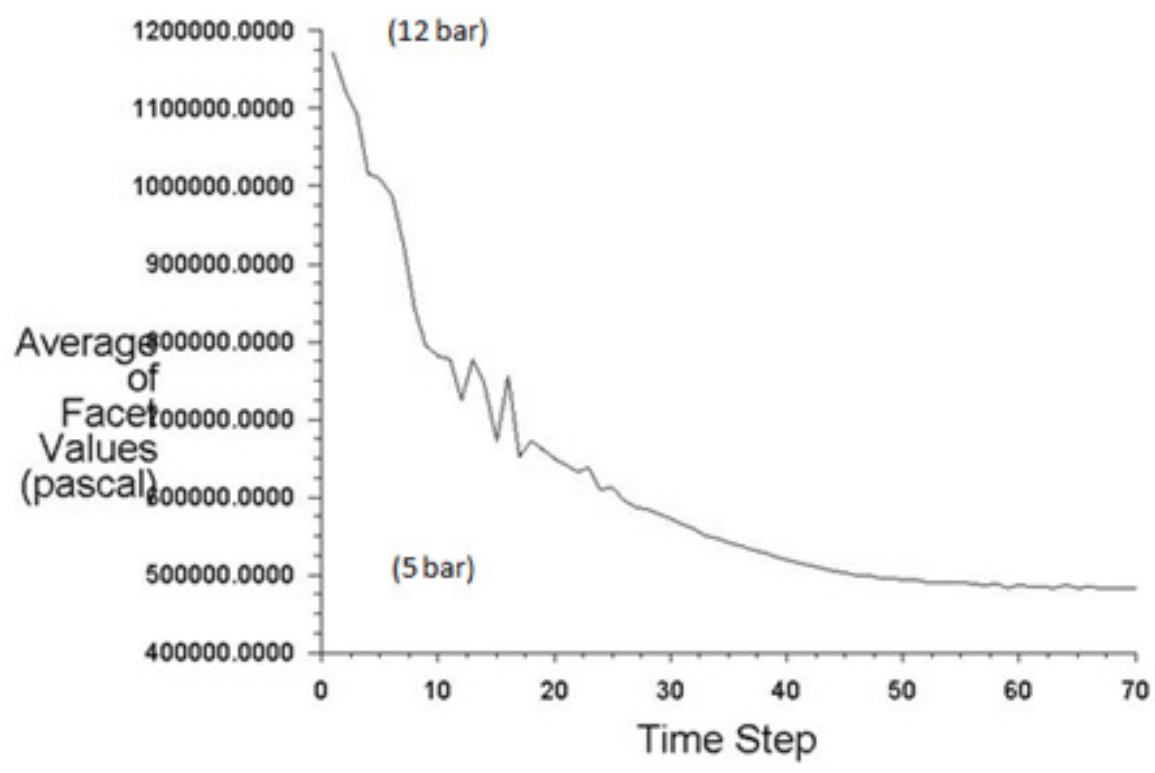

Convergence history of Total Pressure

Figure 3.Pressure at pipe outlet over a period of time. 
Advanced Energy: An International Journal (AEIJ), Vol. 2, No. 4, October 2015

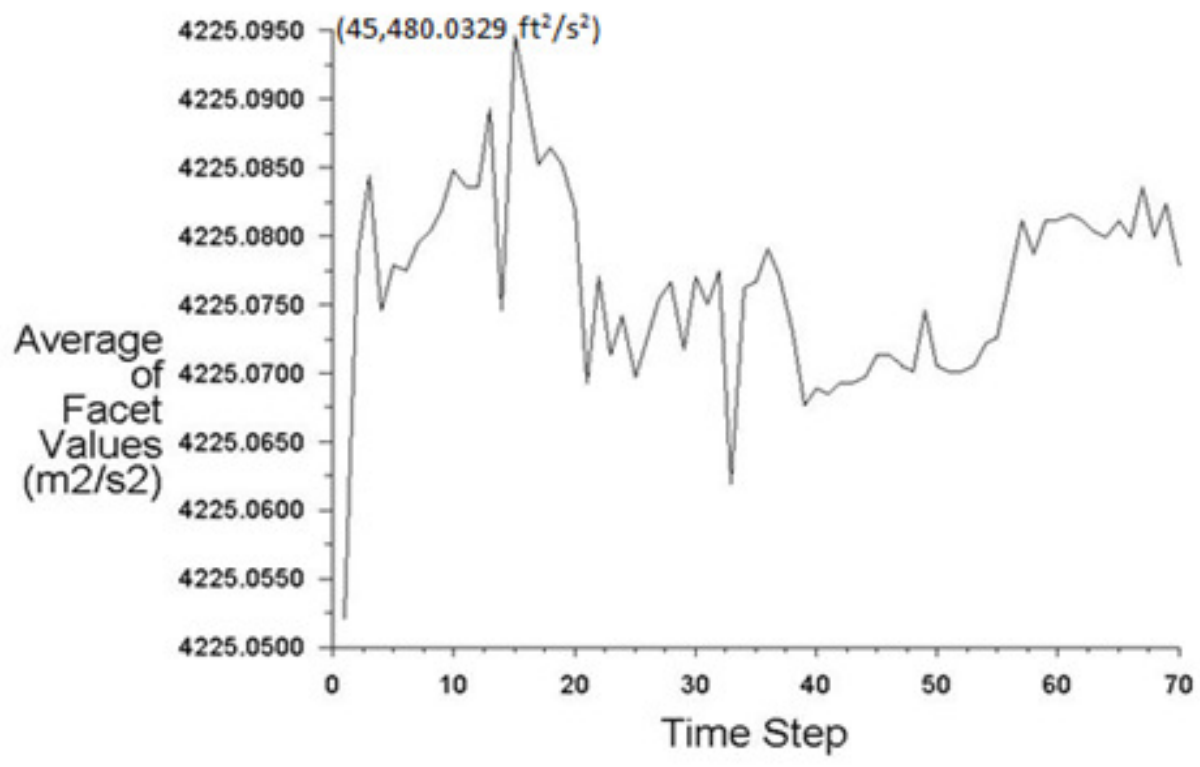

Convergence history of Turbulent Kinetic Energy

Figure 4.Monitoring TKE at pipe outlet over a period of time. 